\title{
Preventing aluminium oxide contamination of dental implant surfaces
}

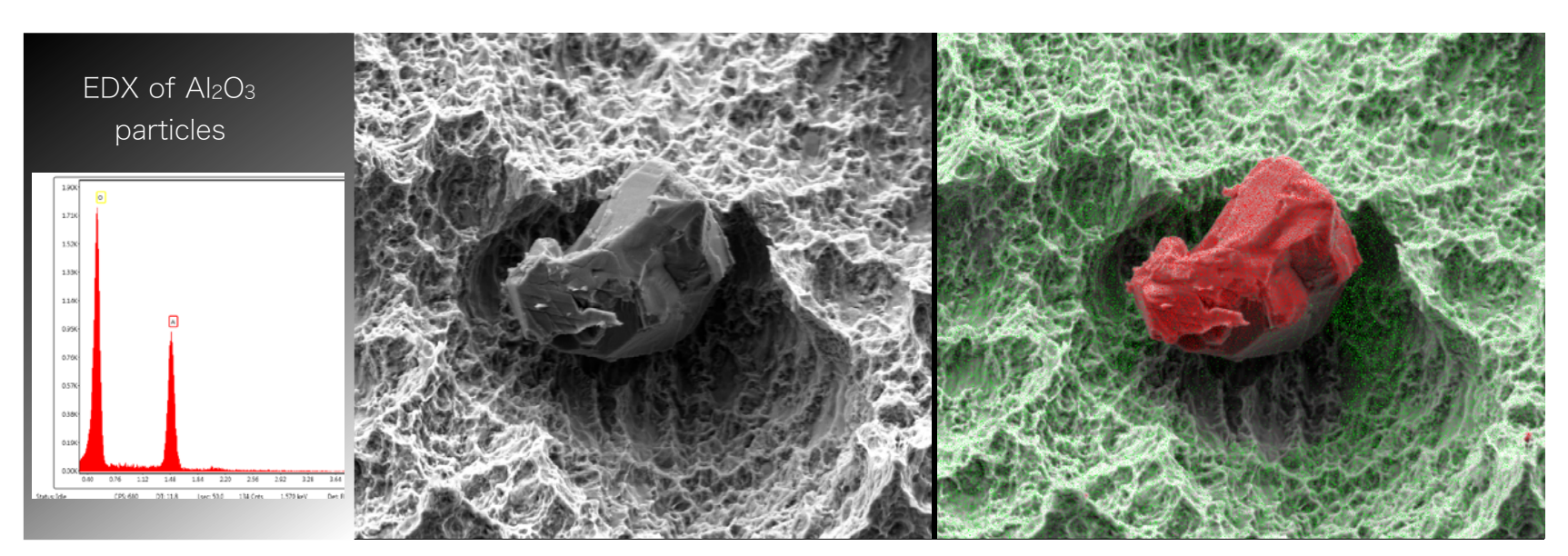

When a dental implant is
inserted, the speed at which it
integrates into the surrounding
bone and tissue, known as
osseointegration, is key to its
eventual success. Treating the
surface of implants to make
them rougher helps this process.
However, contaminants from
this surface modification process
can remain on the implant. A
study carried out by Dr Peter
Schupbach who runs Schupbach
Ltd, a research laboratory for
biomaterials, observed that
aluminium oxide contaminants
were spread on the surfaces
of most commonly used
implant systems. He therefore
advocates the establishment of
controlled surface modification
procedures in all dental implant
manufacturing processes to
ensure clean and consistent
implant systems.

natural tooth is made up of formation of bone on and along the $\begin{array}{ll}\text { a component part seen above } & \text { surface. This process, known as contact } \\ \text { the gum line which is referred } & \text { osteogenesis, is key if the implant }\end{array}$ to as the crown, and another part called the root which lies hidden beneath for securing the crown in place. When a natural tooth is lost, it can be replaced by a false tooth. A dental implant artificially replaces the root of the missing natural tooth, and similar to the role played by the root of the natural tooth, the dental implant secures the crown of the false tooth in its position.

Dental implants are commonly made from titanium. In recent years, titanium implants with a moderately rough surface have become increasingly popular in implant dentistry because of their ability to integrate more rapid into surrounding bone and reduce of the surface (surace the roughness area of the implant and allows a direct

IMPLANT SURFACE

MODIFICATION TECHNIQUES Various methods TECHNIQUES to modify the surface properties of titanium implants, and to roughen the surfaces of the implants. These are based on additive, subtractive, chemical and electrochemical processes. They include sandblasting, anodization, acid-etching, titanium plasma spraying, coating with and sandblasting combined with acid-etching (SA)

The SA technique has been shown to increase the rate and amount of (F) therefore one of the mas employed surface modification of the surface (surface topography

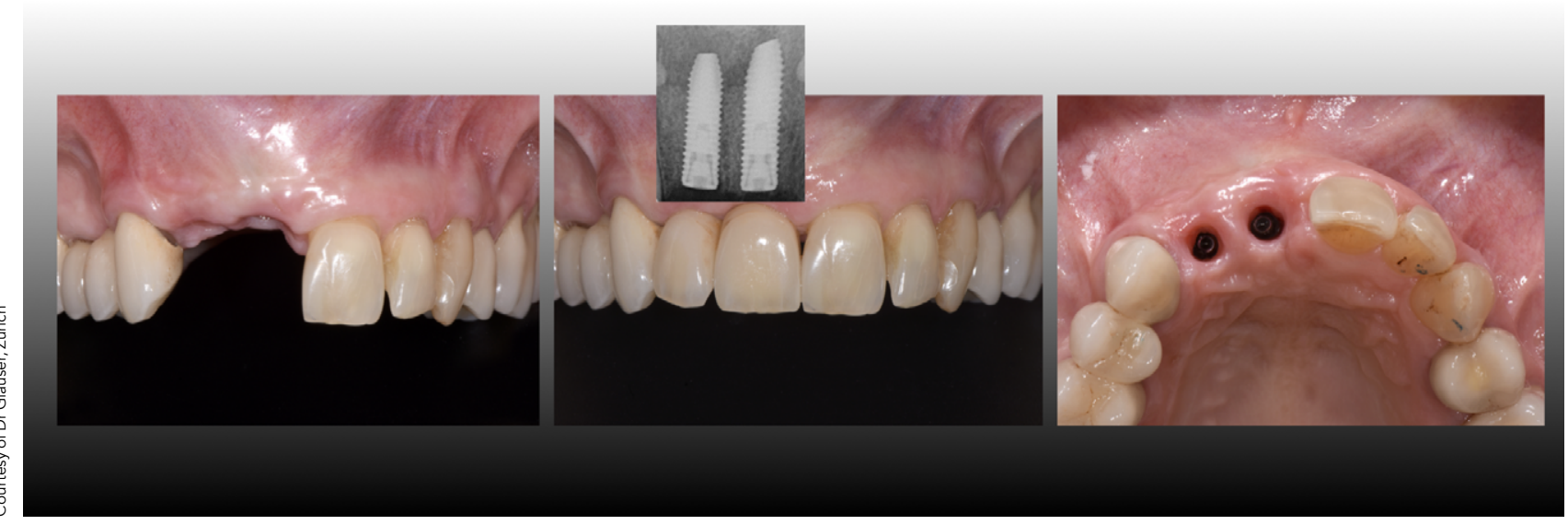

methods used today. SA involves a grit blasting technique where particles suc as aluminium oxide $\left(\mathrm{Al}_{2} \mathrm{O}_{3}\right)$, titanium oxide $\left(\mathrm{H}_{2}\right)$ or Calcium phosphates implants by means of compressed air or fluid through a nozzle at high velocity. The size of the particles can range from ten to several hundred (micrometres). Due to their impact they create small craters on the surface of the machined implants, in the same way that asteroids have created craters on the moon's surface.

Subsequently, they are immersed in a strong acid solution such as $\mathrm{HCl}, \mathrm{H}_{2} \mathrm{SO}_{4}, \mathrm{HF}$ or $\mathrm{HNO}_{3}$ at high temperatures. The aim is to remove any blasting particles left on the surface of the implants and to make further

\section{SURFACE MODIFICATION} CHALLENGES

No doubt modification of the surface positively impacts osseointegration, but an aspect of the process that continues to attract attention is the cleanliness of the resulting implant. surface since the presence of impurities can be harmful to patients.

Previous studies show that different sterile-packaged implant systems with organic and inorganic contaminations on their surfaces abound in the market. This is backed by the pilot study conducted by Duddeck et al (2019) which compared the cleanliness of different oral mplant systems in the market. The study concluded that look-
alike implants revealed significantly higher impurities when compared to original implants of market-leading

The SA and anodization techniques are two of the main surface modifying of the implant systems available in

NEED FOR QUALITY CONTROL The quality of an implant surface cannot be assessed by visual inpection, but must be able to assure physicians that final products meet quality standards. While a large number of studies

Sandblasting combined with acid-etching (SA) is one of the most commonly employed surface modification methods.

the market today. While the anodization have been carried out to investigate process does not lend to particle the surface properties of commercially contamination, the SA process has the available implant systems, there potential of retaining the particles used has been no comprehensive study in the process on the implant surface on the cleanliness of SA-modified even after acid-etching. implant systems.

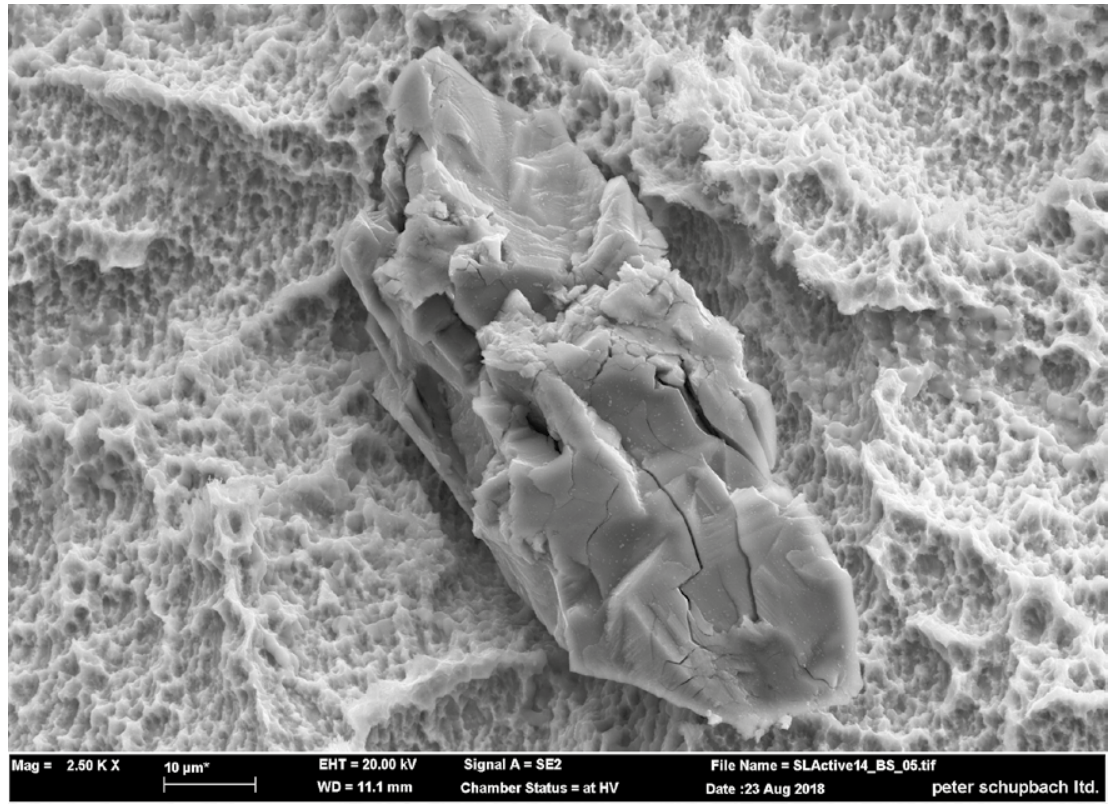

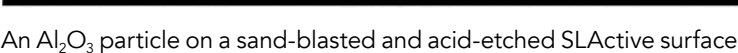




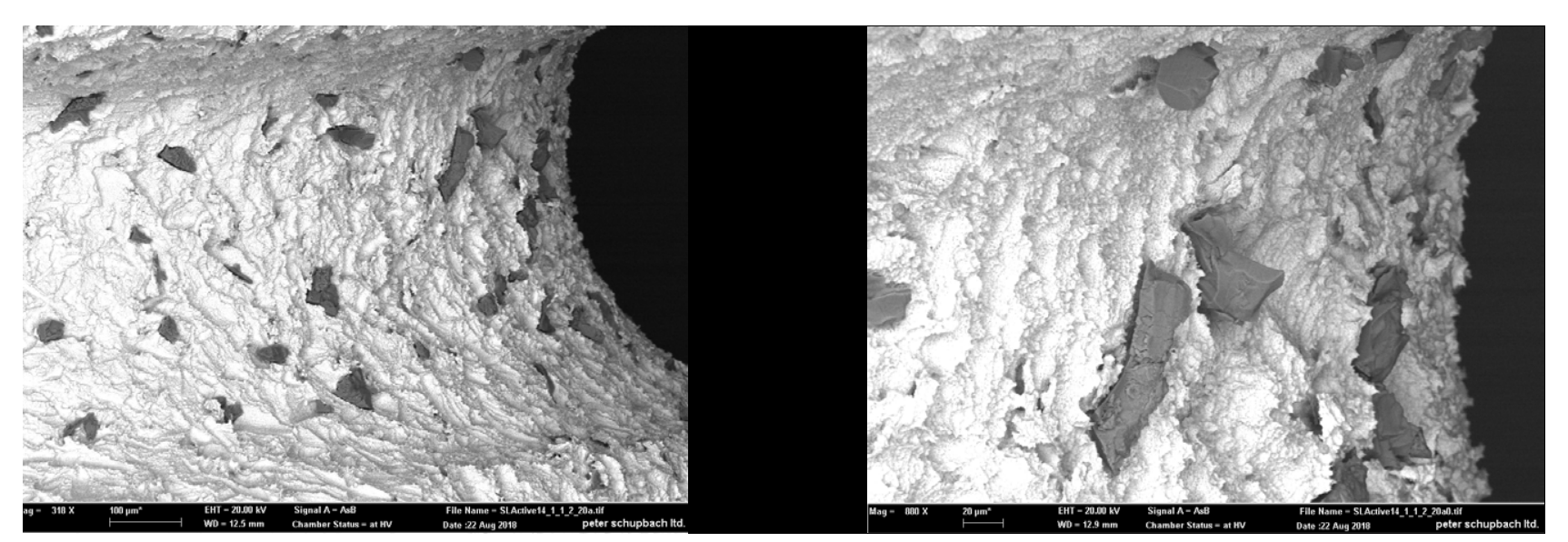

$\mathrm{Al}_{2} \mathrm{O}_{3}$ particles on a sand-blasted and acid-etched SLActive dental implant surface.

Dr Peter Schupbach, a PhD holder in magnification of $\times 64$ were captured Natural Sciences, an Adjunct Professor at the Augusta University, and an author/co-author of 120 peer-reviewed publications conducted an investigation of blasting particle remnants on the in three regions of interest (ROI) corresponding to the three zones. The number of particles in each RO was determined and the particles were marked and numbered. The size surface of nine major, commercially

of each particle was measured using

\section{$\mathrm{Al}_{2} \mathrm{O}_{3}$ particles were present on the} surfaces of most commercially available, sterile-packed, dental implant systems modified with the SA process.

available implant systems produced by seven different manufacturers using the SA technique. The investigation sough to determine if the manufacturing process impacted in any way on the surface cleanliness and reproducibil of any particular surface topography.

A total of 54 implants were analysed. Information on the diameter, length was obtained and their surfaces were analysed by SEM (Scanning Electron Microscopy). Three zones were defined on the implants to evaluate their surfaces, and overview images at a

imaging software and particles smaller than 10 micrometres were discounted. An image of each particle was also taken and its elemental composition determined using EDX (EnergyDispersive X-ray) spectroscopy wit

Apart from one implant system, SEM demonstrated the presence of remnant particles on all the implant showed that the particles were composed of aluminium and oxygen, suggesting that they were remnants of the aluminium oxide particles used
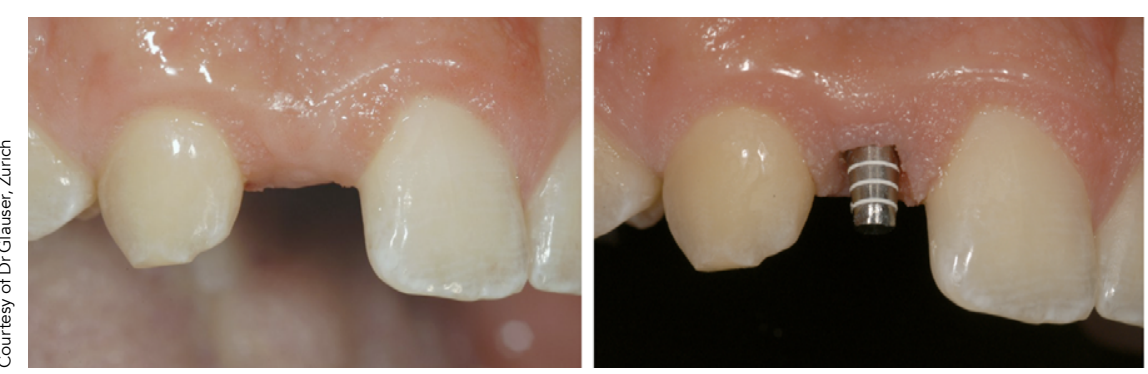

in the blasting process. The results from the investigation demonstrate on the surfas of micle contamination on the surfaces of most commercially available, sterile-packed, dental SA process. Also citing a with the published study Schupbach et al (2019) pointed out that 'these results confirm the findings of a previously published study, which showed that $\mathrm{Al}_{2} \mathrm{O}_{2}$ [aluminium oxide] particles might cover up to $14.4 \%$ of the implant surface' following blasting without etching

CONCLUSION

While dental implants with moderately rough surfaces osseointegrate faster, and the use of surface modifications significant/y decreases early failures, the impact of manufacturing processes Not all mace cleanliness remains. assurance, and as implont surfality quality cannot be assessed by visua inspection, Dr Schupbach posits the adequate process control over surface modification is vital for all dental implant manufacturers to achieve clean and consistent medical devices.

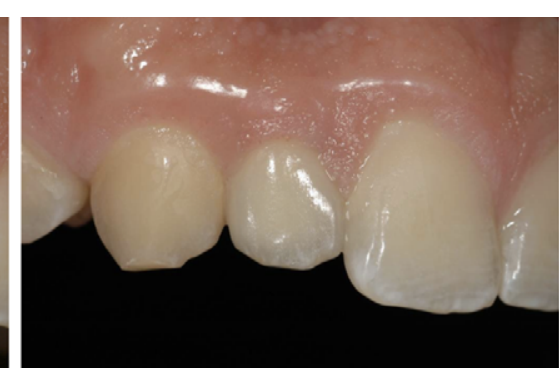

\section{Behind the Research}

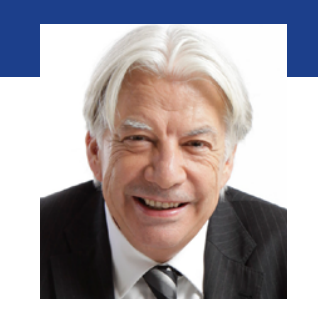

Dr Peter

Schupbach

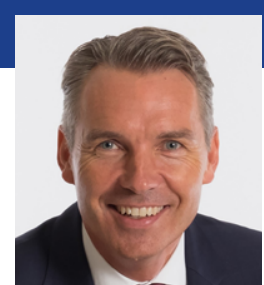

Dr Roland

Glauser

E: pmschupbach@mac.com T: $+41447254879 /+41794332592 \quad$ W: www.schupbachltd.com

\section{Research Objectives}

Dr Schupbach investigates how dental implants are integrated into the bone and how titanium surface

modification can help with this.

\section{Detail}

Schupbach Ltd

Schuetzenstrasse 3

Switzerland

Bio

Dr Schupbach has a PhD in natural sciences. He is author or co-author of 120 peer-reviewed publications. Today he runs a Research Laboratory for Biomaterials in Switzerland. Dr Schupbach is Adjunct Professor at the Augusta University. In 2010 he received both the American Academy of Periodontology Clinical Research Award and the R. Earl Robinson Award.

Dr Glauser runs a private dental clinic in Zürich, Switzerland As an international educator he has held more than 750 workshops and seminars He is a keynote presentations, of more than 70 peer-reviewed publications.

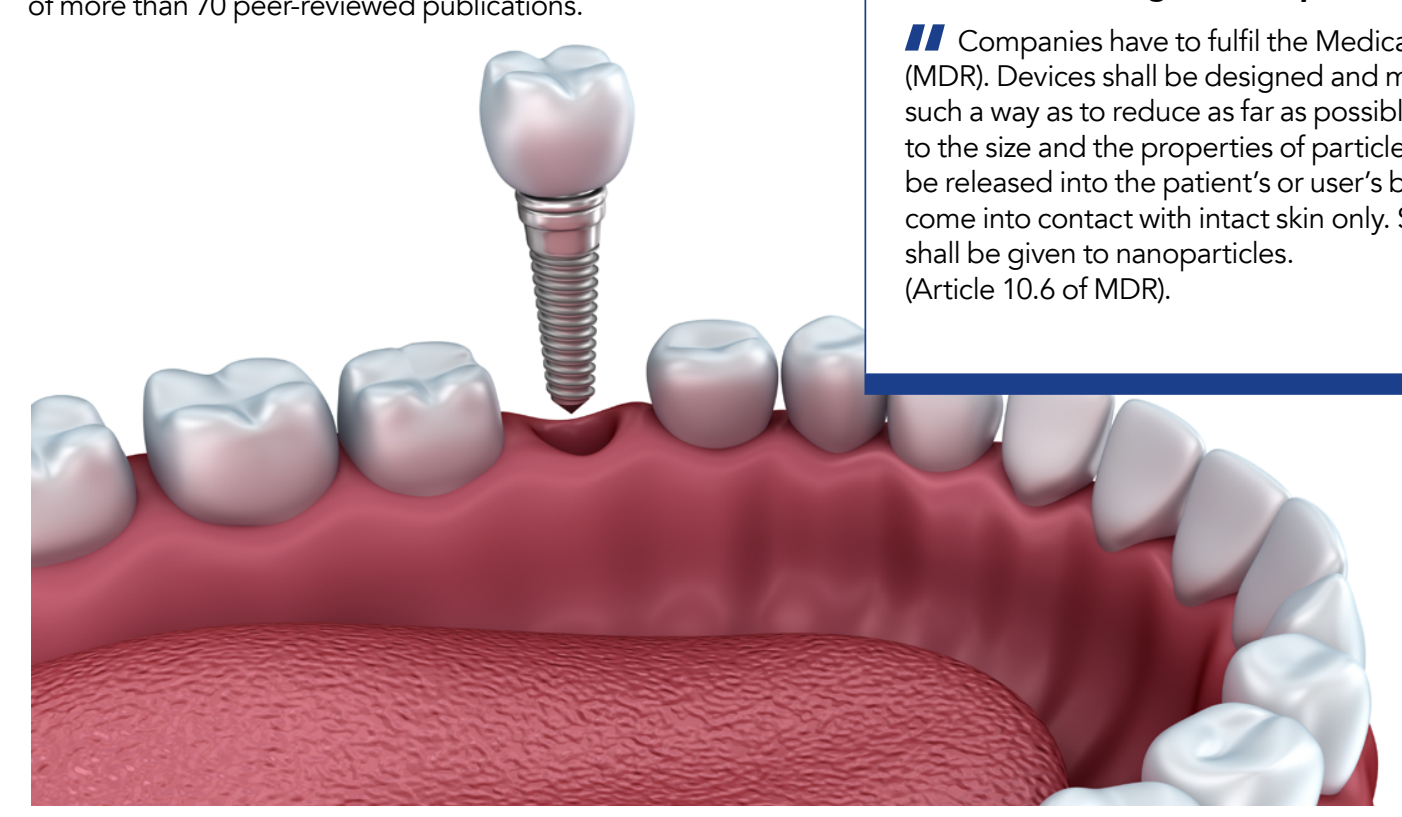

References

Feighan, J, Goldberg, V, Davy, D, Parr, J, Stevenson, S, 1995, 'The influence of surface-blasting on the incorporation of titanium-alloy implants in a rabbit intramedullary model' The Journal of Bone \& Joint Surgery, vol. 77, no. 9, pp. 1380-1395.Available at https://insights.ovid.com/ coosst10/2019)

Duddeck, D, Albrektsson, T, Wennerberg, A, Larsson, C, Beuer, F, 2019, 'On the Cleanliness of Different Oral Implant Systems: A Pilot Study' J. Clin. Med., 8 (9), pp. 1280. Available at https://doi.org/10.3390/icm8091280 (Accessed 03/10/2019)

Schupbach, P, Glauser, R, Bauer, S, 2019, 'Al2O3 Particles on Titanium Dental Implant Systems following Sandblasting and Acid-Etching Process', International Journal of Biomaterials vol. 2019 Article ID 6398429, 11 pages. Avallable at https./// doi.org/10.1155/2019/6318429 (Accessed 03/10/2019)

\section{Personal Response} How will process control on surface modifications
be enforced among dental implant manufacturers?

II Companies have to fulfil the Medical Device Regulation such a way as to reduce as far as possible the risks linked wich or can 作 hall be given to nanoparticles. 